\title{
UWAGI DO REWALORYZACJI TERENU WOKÓŁ ZABYTKOWEGO KOŚCIOŁA PW. ŚW. MARCINA W GRYWAŁDZIE
}

\begin{abstract}
Niniejszy artykuł podejmuje problem rewaloryzacji terenu wokół zabytkowego kościoła pw. św. Marcina w Grywałdzie. Opisano w nim historię świątyni wraz $\mathrm{z}$ udokumentowanymi pracami rewaloryzacyjnymi obiektu oraz jego otoczenia, stan istniejący zespołu oraz wytyczne konserwatorskie do procesu rewaloryzacji zagospodarowania terenu wokół kościoła.

Kościół pw. św. Marcina został wzniesiony w wieku XV i jest jednym z najcenniejszych przykładów sakralnego budownictwa drewnianego w Polsce. Sam obiekt w związku z licznymi pracami renowacyjnymi jakie były tutaj prowadzone w wieku XX oraz na początku XXI jest w dobrym stanie technicznym. Natomiast jego otoczenie, na które składa się: kamienny mur ogrodzeniowy, dwie pary filarów tworzących symboliczne bramy w murze ogrodzeniowym, schody terenowe oraz kamienne dojścia do świątyni, jest w złym stanie technicznym i wymagają pilnej interwencji konserwatorskiej. Interwencja ta winna być poprzedzona opracowaniem wytycznych konserwatorskich w postaci programu prac konserwatorskich przy zabytku, a także projektu budowlano-wykonawczego planowanych prac. Proces rewaloryzacji przedmiotowego terenu winien być prowadzony w uzgodnieniu z Wojewódzkim Konserwatorem Zabytków, gdyż kościół wraz z otoczeniem jest wpisany do Rejestru Zabytków Nieruchomych Województwa Małopolskiego.
\end{abstract}

Słowa kluczowe: zagospodarowanie wokół kościoła, rewaloryzacja, zespół zabytkowy, konserwacja kamienia

\section{Wprowadzenie}

Kościół pw. św. Marcina jest jednym z najstarszych drewnianych kościołów w Małopolsce. Położony jest na wzniesieniu, w niewielkiej podhalańskiej miejscowości Grywałd (ryc. 1-3), nieopodal Krościenka and Dunajcem. Historia powstania samego Grywałdu sięga 1 połowy XIV wieku, kiedy to w dokumentach źródłowych po raz pierwszy wymieniono nazwę Grünewald, czyli Zielony Las [1].

${ }^{1}$ Autor do korespondencji / corresponding author: Dominika Kuśnierz-Krupa, Politechnika Krakowska, Instytut Historii Architektury i Konserwacji Zabytków, ul. Kanonicza 1, 31-002 Kraków; tel. 12 6282419; dkk@zeriba.pl

${ }^{2}$ Michał Krupa, Politechnika Rzeszowska, Zakład Urbanistyki i Architektury, Al. Powstańców Warszawy 12, 35-959 Rzeszów; tel. 17 8651691; mkrupa@prz.edu.pl 


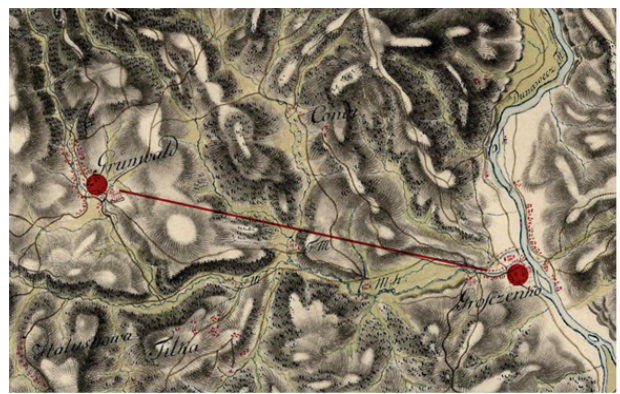

Ryc. 1. Grywałd na XVIII-wiecznej Mapie Miega. Czerwoną linią zaznaczono jego lokalizację względem Krościenka nad Dunajcem. Kopia mapy w Archiwum KHAUiSzP WA PK, s.v.

Fig. 1. Grywałd on Mieg's map from the $18^{\text {th }}$ century. Red line marked its location in relation to Krościenko on the Dunajec. Copy of the map in the Archive KHAUiSzP WA PK, s.v.

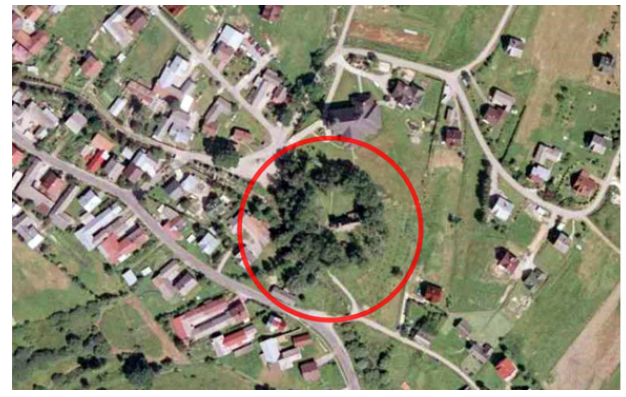

Ryc. 3. Kościół pw. św. Marcina w Grywałdzie na ortofotomapie. Stan istniejący

Fig. 3. The St. Martin church in Grywałd in the orthophotomap. Present state

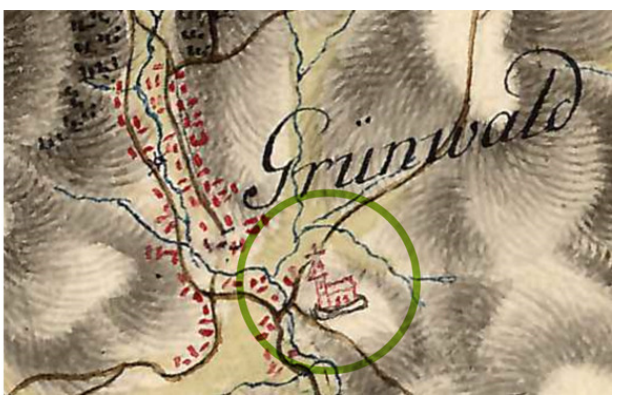

Ryc. 2. Grywałd na XVIII-wiecznej Mapie Miega. Zielonym kołem zaznaczono lokalizację kościoła pw. św. Marcina. Kopia mapy w Archiwum KHAUiSzP WA PK, s.v.

Fig. 2. Grywałd on Mieg's map from the $18^{\text {th }}$ century. Green circle marked location of the church of St. Martin. Copy of the map in the Archive KHAUiSzP WA PK, s.v.

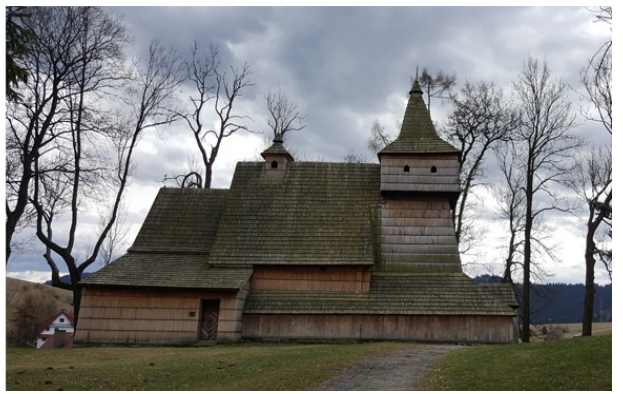

Ryc. 4. Kościół pw. św. Marcina w Grywałdzie w widoku od północy. Stan istniejący. Fot. D. Kuśnierz-Krupa, 03.2016 r.

Fig. 4. The St. Martin church in Grywałd, view from the north. Present state. Photo by D. Kuśnierz-Krupa, 03.2016

Kościół z kolei datowany jest na wiek XV, co czyni go jednym z najcenniejszych tego typu zabytków w Polsce. Sama świątynia w wieku XX i na początku XXI (ryc. 4-8) przeszła kilka remontów konserwatorskich w związku $\mathrm{z}$ czym jest $\mathrm{w}$ dobrym stanie technicznym. W znacznie gorszej kondycji jest otoczenie kościoła, na które składają się: mur ogrodzeniowy z dzikiego kamienia; schody terenowe prowadzące na wzniesienie kościelne od południa (również wykonane z dzikiego kamienia); dwie pary filarów tworzące symboliczne bramy (od północy i zachodu) w murze ogrodzeniowym; schody terenowe prowadzące do kościoła od północy oraz dojścia do świątyni (od północy i zachodu). W związku z powyższym postuluje się przeprowadzenie na terenie wokół ko- 
ścioła (który także podlega ochronie) pilnych prac konserwatorskich, polegających przede wszystkim na zahamowaniu degradacji wyżej wymienionych kamiennych elementów.

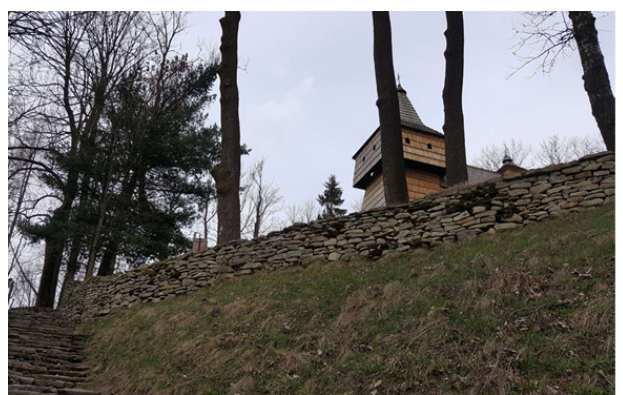

Ryc. 5. Kościół pw. św. Marcina w Grywałdzie. Widok od południa na fragment muru ogrodzeniowego oraz schodów terenowych. Fot. D. Kuśnierz-Krupa, 03.2016

Fig. 5. The St. Martin church in Grywałd. View from the south onto fragment of the surrounding wall and outside stone steps. Photo by D. Kuśnierz-Krupa, 03.2016

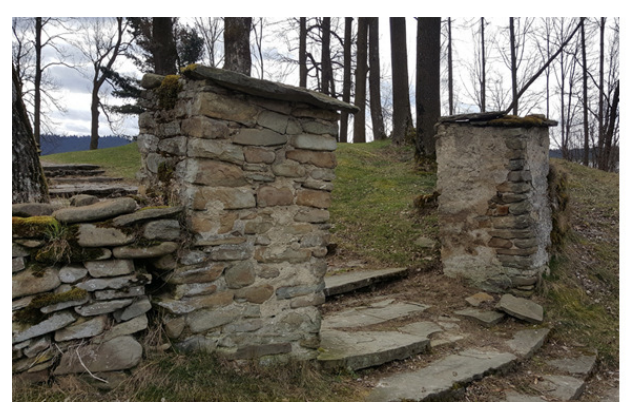

Ryc. 7. Kościół pw. św. Marcina w Grywałdzie. Widok od północnego-wschodu na fragment muru ogrodzeniowego oraz filary. Fot. D. Kuśnierz-Krupa, 03.2016

Fig. 7. The St. Martin church in Grywałd. View from the north-east onto a fragment of the surrounding wall and columns. Photo by D. Kuśnierz-Krupa, 03.2016

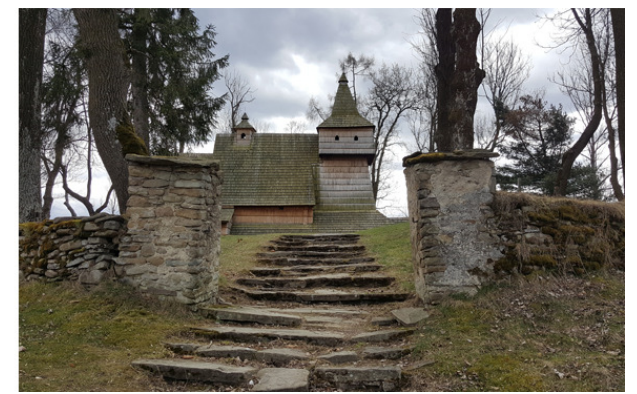

Ryc. 6. Kościół pw. św. Marcina w Grywałdzie. Widok na filary z dzikiego kamienia tworzące symboliczną bramy (od strony północnej) w murze ogrodzeniowym. Fot. D. KuśnierzKrupa, 03.2016

Fig. 6. The St. Martin church in Grywałd. View onto columns from rough stone creating symbolic gates (from the north) in the surrounding wall. Photo by D. Kuśnierz-Krupa, 03.2016

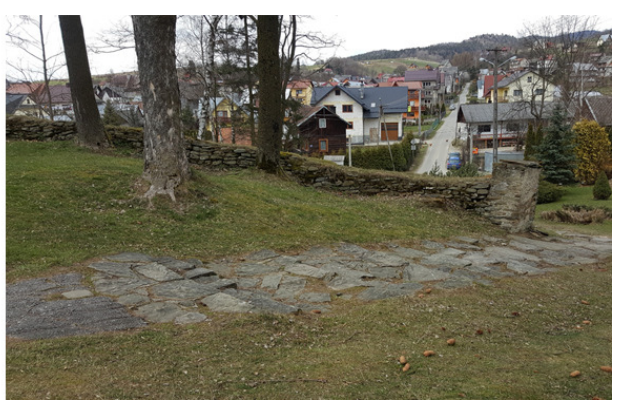

Ryc. 8. Kościół pw. św. Marcina w Grywałdzie. Widok od wschodu na schody terenowe poprowadzone od bramy północnej. Fot. D. Kuśnierz-Krupa, 03.2016

Fig.8. The St. Martin church in Grywałd. View from the east onto outside stone steps running from the north gate. Photo by D. KuśnierzKrupa, 03.2016 


\section{Rys historyczny obiektu oraz opis prac rewaloryzacyjnych prowadzonych przy obiekcie w przeszłości}

Pierwsza parafia w Grywałdzie powstała przed 1330 rokiem, co potwierdza zapis w akcie lokacyjnym wsi Kamienica, w którym wymieniono Filipa, plebana z Grywałdu. Jak pisze, M. Kornecki okręg parafialny był pierwotnie niewielki i obejmował samą wieś [2].

Przedmiotowy kościół jest obiektem drewnianym wzniesionym w 2 połowie XV wieku. Kościół początkowo uważany był przez badaczy (K. i T. Mokłowskich) za cerkiew unicką. Także jego datowanie podlegało wielu weryfikacjom. T. Spiss datował go na równi z kościołem z Dębna na wiek XIII [3], a F. Kopera na 2 połowę XVIII wieku [4]. Dopiero po wielu analizach obiektu oraz po skonfrontowaniu jego kształtu z innymi kościołami z terenu Podhala ustalono okres jego powstania na 2 połowę XV wieku [5].

Badania architektoniczne kościoła pod kątem zachowania jego pierwotnej struktury przeprowadzono w połowie XX wieku. Wykazały one, że jedynie zrąb ścian nawy i prezbiterium oraz wschodnia ściana zakrystii są jednorodne, a pozostałe elementy pochodzą z okresu późniejszego. R. Brykowski, jeden z największych badaczy zabytkowej architektury drewnianej, a szczególnie obiektów sakralnych, twierdzi, że elementy te powstały w 1 połowie wieku XVII, kiedy to kościół został gruntownie przebudowany [6]. Przebudowa ta musiała nastąpić zapewne przed 1618 rokiem, kiedy to miała miejsce realizacja kościelnej polichromii [7]. Podczas ówczesnych prac budowlanych przy obiekcie zmieniono więźbę dachową, stropy, a także, jak pisze Brykowski, obniżono zrąb ścian i zlikwidowano zaskrzynienia [8].

Kościół pw. św. Marcina reprezentuje starszy typ kościołów drewnianych w Małopolsce. Głównym akcentem budowli jest wieża, szeroko posadowiona, o ścianach silnie zwężających się ku górze, z wydatnie nadwieszoną izbicą. Malowniczość kościoła podkreślają oszalowane soboty [9]. Kościół posiada tradycyjny rzut, w którym zarówno nawa jak i prezbiterium oparte są na planie kwadratu. W prezbiterium i w nawie zachowała się polichromia z 1618 r. Do wyposażenia świątyni należą trzy ołtarze. W ołtarzu głównym umieszczono interesujący tryptyk późnogotycki z pocz. XVI wieku [10].

Prócz opisanych wyżej prac remontowych prowadzonych w 1 połowie XVII wieku, kolejne odnotowane w źródłach przeprowadzono dopiero w 1845 roku, kiedy powiększono zakrystię i wzniesiono kruchtę od strony południowej.

Na początku wieku XX kościół był zaniedbany, w związku z czym zaplanowano jego remont oraz rozbudowę. W roku 1930 opracowano w tym celu projekt architektoniczny (proj. arch. Zygmunt Gawlik), który oprócz remontu zakładał również dobudowę dwóch bocznych kaplic. Ostatecznie jednak nie został on zrealizowany. Remont świątyni rozpoczęto dopiero siedem lat później i objął on naprawę fundamentów, fragmentaryczną wymianę podwaliny i części bier- 
wion ścian. Podczas przedmiotowych prac wzmocniono także konstrukcję sobót oraz wieży, która była wówczas w złym stanie technicznym. Kościół otrzymał także nowe pokrycie dachowe w postaci tradycyjnego gontu. Remont ten prowadzono stopniowo i trwał on także podczas II wojny światowej, kiedy to uporządkowano wzgórze, na którym zlokalizowana jest świątynia. Wykonano wówczas odwodnienie, a także poprawiono i uzupełniono ogrodzenie z dzikiego kamienia [11]. Kolejny remont kościoła został przeprowadzony w latach 60-tych XX wieku [12], zaś następny, obejmujący rozległe prace konserwatorskie we wnętrzu obiektu, w latach 2008-2010.

\section{Kościół pw. św. Marcina obecnie}

Kościół pw. św. Marcina w Grywałdzie w wieku XX oraz na początku XXI wieku przechodził kilka remontów konserwatorskich, z których większość została wymieniona wyżej. W związku z czym wydaje się on być $\mathrm{w}$ dobrym stanie technicznym. Natomiast elementy małej architektury, wykonane z dzikiego kamienia, takie jak schody terenowe prowadzące od południa na wzniesienie, na którym położony jest obiekt; dwie symboliczne bramy w murze ogrodzeniowym (w postaci filarów z dzikiego kamienia) oraz ciągi piesze prowadzące od bram do kościoła, są w złym stanie technicznym. Można zaryzykować stwierdzenie, że ostatni kompleksowy remont konserwatorski tych elementów zagospodarowania terenu wokół świątyni miał miejsce w połowie XX wieku, o czym wspomina w swoim opracowaniu M. Kornecki [13].

Prawdopodobnie w ciągu następnych 60 lat prowadzono jedynie drobne prace naprawcze polegające m.in. na założeniu metalowej balustrady przy schodach terenowych, na uzupełnieniu zaprawy oraz brakujących elementów schodów terenowych, muru kościelnego, bram oraz traktów pieszych. Część z tych prac, prowadzonych jeszcze w wieku XX, zapewne z powodu braku środków finansowych, była wykonywana nieprofesjonalnie, metodą gospodarczą. Toteż ich efekt był krótkotrwały, a stan techniczny przedmiotowych elementów zagospodarowania terenu wokół kościoła stale się pogarszał.

W związku z powyższym postuluje się przeprowadzenie pilnych prac rewaloryzacyjnych przy wymienionych elementach zagospodarowania terenu wokół świątyni, zgodnie ze sztuką konserwatorską oraz zasadami wiedzy technicznej.

\section{Program prac konserwatorskich przy elementach zagospodarowania terenu wokół kościoła pw. św. Marcina w Grywałdzie}

Program prac konserwatorskich otoczenia kościoła dotyczy rewaloryzacji wymienionych już wcześniej elementów zagospodarowania terenu takich jak: mur ogrodzeniowy; schody terenowe prowadzące na wzniesienie kościelne od 
południa; dwie pary filarów tworzące w murze ogrodzeniowym dwie symboliczne bramy (od północy i zachodu); schody terenowe prowadzące do kościoła od północy oraz dojścia do świątyni (od północy i zachodu). Wszystkie te elementy wykonane zostały $\mathrm{z}$ dzikiego lokalnego kamienia (z granitu oraz piaskowca). W związku z tym procedura ich rewaloryzacji jest bardzo podobna. Przy ich konserwacji należy wykorzystać produkty dedykowane do renowacji naturalnego konserwacji.

Pierwszym krokiem $\mathrm{w}$ procesie konserwacji przedmiotowych elementów winno być usunięcie $\mathrm{z}$ ich powierzchni (poprzez skucie) pozostałości starych zapraw, będących skutkiem doraźnych remontów. Następnie elementy te należy wyczyścić na sucho, np. metodą strumieniowo-ścierną z wykorzystaniem urządzenia o stycznym kącie uderzenia ścierniwa do czyszczonej powierzchni, co redukuje ryzyko powstania uszkodzeń kamienia. Kolejnym krokiem w przedmiotowym procesie jest usunięcie (przy pomocy właściwego środka) z rewaloryzowanych obiektów soli, grzybów, pleśni, glonów i innych zabrudzeń, których nie usunięto podczas czyszczenia metodą strumieniowo-ścierną. Te kamienie, które są w szczególnie złym stanie należy wzmocnić. Zabieg wzmocnienia można podzielić na dwa etapy: wzmocnienie wstępne (przed czyszczeniem) i wzmocnienie zasadnicze. Do wzmocnienia należy użyć preparatu na bazie czystego (pozbawionego rozpuszczalników organicznych) krzemianu etylu z dodatkiem katalizatora, który zapewni doskonałą penetrację na dużą głębokość. Takie elementy jak schody terenowe czy dojścia do kościała wykonane z kamienia winny być przełożone i uzupełnione identycznym do oryginalnego materiałem (dziki kamień lokalny). Należy przy tym dążyć do otrzymania możliwie płaskiej powierzchni, wygodnej dla użytkowników. Z kolei w przypadku prac konserwacyjnych przy kamiennych filarach należy uzupełnić spoinowanie kamienia. Można tutaj zastosować zaprawę, która jest zarabianą emulsją żywicy epoksydowej w wodzie, dzięki czemu otrzymuje się elastyczny materiał, a spoiny nie wykruszają się przy naprężeniach [14].

Reasumując należy dodać, że z uwagi na prawdopodobne podciąganie kapilarne wilgoci nie jest wskazana impregnacja przedmiotowego kamienia. Zwężenie kapilar poprzez impregnację zmniejsza dyfuzję pary wodnej, co może w przyszłości doprowadzić do jego uszkodzeń.

\section{Podsumowanie}

W podsumowaniu niniejszego artykułu należy zwrócić uwagę na istotę problemu jakim jest zły stan techniczny elementów zagospodarowania wokół kościoła pw. św. Marcina w Grywałdzie, który jest jednym z najcenniejszych zabytków sakralnych Małopolski. Elementy tworzące otoczenie świątyni kreują krajobraz kulturowy wzgórza kościelnego. Są one, tak samo jak kościół, wpisane do Rejestru Zabytków Nieruchomych Województwa Małopolskiego, zatem winny podlegać ochronie. W związku z powyższym należy przeprowadzić tutaj 
pilne prace konserwatorskie, zgodnie ze wskazaniami ujętymi w programu prac konserwatorskich, a także w uzgodnieniu z właściwym Urzędem Ochrony Zabytków.

\section{Literatura}

[1] Stownik geograficzny Królestwa Polskiego i innych krajów słowiańskich, F. Sulimierski, B. Chlebowski, W. Walewski (red.), Wyd. Zakładem F. Sulimierskiego i W. Walewskiego, Warszawa 1880, T. XV cz. 1, s.v.

[2] Kornecki M., Gotyckie kościoły drewniane na Podhalu, Wyd. Literackie, Kraków 1987, s. 96.

[3] Spiss T., Wykaz drewnianych kościołów i cerkwi w Galicji, Lwów 1912, s. 49.

[4] Kopera F., Kościoły drewniane w Galicji Zachodniej, seria I, Kraków 1915, z. 2-3, ss. 101-105.

[5] Szydłowski T., Zabytki sztuki w Polsce. Inwentarz topograficzny, cz. III, woj. Krakowskie, T. 1, z. 1, Powiat nowotarski, Warszawa 1938, ss. 59-62.

[6] Brykowski R., Drewniana architektura kościelna w Matopolsce w XV wieku, Wyd. PAN, Wrocław, Warszawa, Kraków, Gdańsk, Łódź 1981, s. 214.

[7] Brykowski R., Kornecki M., Drewniane kościoły w Małopolsce Potudniowej, Wyd. Ossolineum, Wrocław-Warszawa-Kraków-Gdańsk-Łódź 1984, s.72.

[8] Brykowski R., op. cit, s. 214.

[9] Szydłowski T., op. cit, s. 8.

[10] M. Kornecki, op. cit., ss. 96-97.

[11] Ibidem.

[12] R. Brykowski, M. Kornecki, op. cit., s. 72.

[13] M. Kornecki, op. cit., s. 97.

[14] Katalog produktów firmy Remmers Polska.

\section{REMARKS ON REVALORISATION OF THE AREA AROUND HISTORIC CHURCH OF ST. MARTIN IN GRYWAŁD}

\section{S u m m a r y}

The paper addresses the issues of revalorisation of the area around the historic St. Martin's in Grywałd. The history of the church with documented revalorization work in the object and its surroundings, the existing state of the complex and conservation guidelines for the revalorization process of the church premises were described here.

St. Martin's church was erected in the 15th century and is one of the most valuable examples of wooden church buildings in Poland. In connection with intensive revalorisation work carried out during the 20th century and the first part of the 21th century, the object itself is in good state of preservation. However, its surroundings which include: the surrounding stone wall, two pairs of columns creating symbolic gates in the surrounding wall, outside stone steps and stone-paved path to the church, are in the poor condition and require urgent conservation intervention. This intervention should be preceded by preparing conservation guidelines in the form of the Program of Conservation Work on the object, as well as a building project of future work. The revalorisation process of the discussed area should be carried out in agreement with 
the Voivodeship Monument Conservator because the church and its premises are entered into the Lesser Poland Heritage Register.

Keywords: development of church premises, revalorisation, historic complex, stone conservation

DOI:10.7862/rb.2016.204

Przestano do redakcji: 06.06.2016 $r$.

Przyjęto do druku: 30.11.2016 r. 